\title{
Programa de Saúde da Família e Saúde M ental: impasses e desafios na construção da rede
}

\author{
The Family $\mathrm{H}$ ealth Program and $\mathrm{M}$ ental $\mathrm{H}$ ealth: \\ difficulties and challenges for building a network
}

Vládia Jamile dos Santos Jucá ${ }^{1}$

M ônica de Oliveira Nunes ${ }^{2}$

Suely Galvão Barreto ${ }^{3}$

${ }^{1}$ Departamento de Ciências Humanase Saúde, UNIFACS. Alameda das Espamódias 915. Prédio de Aulas 8, Caminho das Árvores. 41820-460 Salvador BA. vladiajuca@gmail.com

${ }^{2}$ Instituto deSaúde

Coletiva, UFBA.

${ }^{3}$ Escola Baiana de M edicina eSaúdePública.
Abstract Thispaper is fruit of an investigation called "The dynamics of mental care: signs, meanings and practices of professionals working in the Family $\mathrm{H}$ ealth Program (FHP) and in the Psychosocial Care Centers (PCCs)". The main objective of this study was to understand how health professionals working in these two services interpret mental suffering and how they plan and develop their interventions for reducing it. To this purpose, we selected qualitative fieldwork methods that included interviews with the professionals and observation of the practices they develop in the context of the mentioned services. In this work, we present the data produced with regard to the FHP, where we also established focal groups with professionals. The data obtained were later analyzed on the basis of previously defined categories. As a result, we have been able to pin down a number of difficulties the professionals were facing, ranging from theidentification of mental suffering to thechallenge of dealing with specific situations and to the questions involved with the referral to specialized services. On the other hand, the degree of sensibility to social suffering demonstrated by these professionals and their ability to articulate it with psychological suffering deserve to be emphasized.

Key words Family Health Program, Psychosocial Care Center, $M$ ental health, $M$ eanings, Practices
Resumo 0 presente artigo é fruto de uma pesquisa denominada "A dinâmica do cuidado em saúdemental: signos, significados e práticas de profissionais no PSF e no CAPS", cujo objetivo central era compreender como os profissionais de saúde interpretam o sofrimento mental e, para reduzi- Io, planejam edesenvolvem suas intervenções em dois contextos: PSF e CAPS. Para tanto, fizemos um trabalho de campo que envolve desde observação eacompanhamento de práticas desenvolvidas pel os profissionais dos serviços em questão atéentrevistas com os mesmos. A presentaremos, nessemomento, os dados produzidos acerca do PSF, em que, além das estratégi as acima descritas, foram também realizados gruposfocais. Os dados foram posteriormente analisados a partir de categorias previamentedefinidas. Como resultados, foi possível identificar que os profissionais experenciam dificuldades diversas que vão desde a identificação do sofrimento mental, passando pel os impasses relativos ao manejo de situações espećíficas até as questões relativas ao encaminhamento para os serviços especializados. Por outro lado, éimportantedestacar o quanto os profissionais se mostraram sensíveis ao sofrimento social, articulando-o, inclusive, ao sofrimento psíquico.

Palavras-chave Programa de Saúde da Família, Centro de A tenção Psicossocial, Saúde mental, Significados, Práticas 


\section{Introdução}

A assistência em saúde mental tem passado, no Brasil, por um processo demudança, movido principalmente pela reforma psiquiátrica. Segundo Vasconcellos¹, após a década de 1990, tal processo seintensificou eincorporou outras estratégias, além do atendimento ambulatorial, pensado como uma possível alternativa na década de 1980. A proposta de criação dos Centros de Atenção Psicossocial (CAPS) ganha força e outra preocupação emerge - a de envolver a rede de atenção básica na assistência à saúde mental. Por esse motivo, o Programa de Saúde da Família (PSF) se torna um elo importante na identificação e acompanhamento de alguns casos em que o sofrimento mental estivesse presente. A idéia é que os profissionais do PSF encaminhem para os CAPS apenas os que re almente precisam deuma atenção maisespecializada por certo tempo. Para tal idéia funcionar, no entanto, é necessário que haja uma capacitação adequada dos profissionais de ambos os serviços, não apenas com relação ao conhecimento técnico específico de cada área, mas no tocante ao que nos parece fundamental: desenvolver habilidades para realizar parcerias e construir uma rede que surge como a base para uma mudança estrutural no cuidado com a saúde mental.

Em uma perspectiva histórica, é importante notar que a proposta de criação dos Centros de Atenção Psicossocial surge em paralelo com a implementação do Programa de Saúde da Família. Ambos respondem, de certo modo, ao processo de redemocratização no país que, no âmbito da saúde, teve como marcos a reforma sanitária e a tentativa de viabilizá-la através da criação do Sistema Único de Saúde. Obviamente que, apesar de compartilharem o contexto sócio-histórico que possibilitou suas respectivas emergências, os dois serviços em questão têm também histórias independentes, tendo a reforma psiquiátrica um peso maior na instituição dos CAPS. M esmo assim, o movimento da reforma psiquiátrica que, no Brasil, articula-se com o SUS, especialmentenas instituições públicas, defende que a prática de referência e contra-referência seja um marco nas novas formas de assistência. Está assim preconizado, formalmente, queCAPS ePSF deverão trabalhar conjuntamente, como acima discutimos. Com relação especificamenteà organização das práticas de saúde voltadas para a família, é importante destacar seus pressupostos que, segundo Cordeiro $^{2}$, seriam: a saúde como um direito de cidadania e que expressa qualidade de vida; eleição da família como núcleo básico de abordagem no atendimento à saúde; democratização do conhecimento, organização e produção da saúde; intervenção sobre os fatores de risco; prestação à atenção integral no domicílio, no ambulatório e no hospital; a humanização e busca de satisfação do usuário; estímulo à organização comunitária para fins de que a mesma possa exercer seu potencial decontrolesocial; e 0 estabelecimento de parcerias.

Particularmente, sobre a saúdemental na atenção básica, ainda existe pouca discussão teórica e análise crítica acerca das tentativas de implementar ações nesse sentido. Dentre o que há produzido, certamente o trabalho de Lancetti ${ }^{3}$ merece destaque. Em seu livro, o autor e seus colaboradores relatam ediscutem a experiência de uma equipe de saúde mental volante que atua junto ao PSF, na cidade de São Paulo.

Encontramos ainda al gumas considerações interessantes no texto "A Saúde Mental no Programa deSaúde da Família" de O liveira eColvero ${ }^{4}$, no qual as autorasutilizam al gumasidéias deSarraceno para sustentar que: [...] um trabalho de saúde mental na comunidade, visando à promoção, prevenção e o tratamento dos casosidentificados, precisa apoiar-senum conjunto de ações que visem 'o melhoramento ou a manutenção da saúde da população'. Estas ações organizam dentro da 'lógica extramural', eda 'lógica da reconstrução da cidadania plena'.

Considerando a importância de dispositivos de saúde que funcionem regionalmente, com alto nível de integração com as comunidades atendidas, pode-se dizer que tanto o PSF como o CAPS são de extrema relevância para a efetivação do atendimento "extra-mural". Outro lembrete pertinente trazido no texto das autoras e que reforça a importância da participação do PSF na rede decuidados dirigidos ao sofrimento mental diz respeito ao destaque dado ao contexto familiar na atenção em saúde mental. Afinal, esse contexto participa do surgimento e manutenção do sofrimento do sujeito em particular e da própria família.

Com o intuito de iniciar pesquisas que acompanhem as tentativas de concretização das mudanças acima assinaladas, foi realizada em Salvador uma investigação que objetivava compreender como os profissionais de saúde interpretam o sofrimento mental e, para reduzi-lo, planejam e desenvolvem suas interven ções nos seguintes contextos: PSF e CAPS. N esse artigo, serão apresentados os resultados concernentes ao primeiro serviço. Destacaremos, a seguir, o modo pelo qual os profissionais de uma das equipes de PSF existentes em Salvador significam o sofrimento mental e como lidam com o mesmo, destacando os impasses vivenciados para que, a partir dessa detecção, pos- 
samos refletir melhor sobre o suporte necessário para que tais profissionais possam levar adiante as transformações preconizadas.

\section{M etodologia}

$\mathrm{N}$ a realização da pesquisa, foi utilizado um marco teórico desenvolvido especificamente para

pesquisa em saúde mental: o "sistema de signos, significados e de práticas" (Sssp) que prima pela conjugação de análises do tipo semiológico, semântico epragmático, dando ênfaseà uma abordagem fenomenológica que valoriza a reconstrução de casos concretos ea experiência dos atores. A apresentação mais detalhada dos fundamentos dessa abordagem metodológica se encontram em dois textos, elaborados pelos mesmos pesquisadores que a construíram: 1) "Signs, meanings and practices in mental health: methological application. The Bahia Study", escrito por Almeida-Filho et al.5; e 2) "Rethinking transcultural approaches to mental health research: from epistemology to methodology", redigido por Almeida-Filho, Corin e Bibeau'.

A nomenclatura adotada - "signos, significados e práticas" - delimita claramente as três instâncias investigadas durante a pesquisa. Os "signos" se referem aos sinais que são socialmenteconsiderados como indicadores de um determinado fenômeno, passível de interpretações, que correspondem ao nível dos "significados". Por último, temos a dimensão pragmática, onde se considera que a produção cultural é factualmente orientada, ou seja, a cultura se realiza como um fruto da imersão dos sujeitos no mundo, propiciada pela experiência de cada um. Por isso, a reconstrução de casos e a participação dos atores nos mesmos são de extremo valor. Tendo como interesse uma perspectiva que possa vir a ser transcultural e comparativa, a identificação designos de problemasmentais nesta pesquisa pauta-se em uma lista de comportamentos prototípicos observados de forma recorrente e consistente em diversos países. Esta lista é usada como ponto de partida para localizar, no grupo estudado, aqueles signos utilizados pelos entrevistados e seus significados. Vale ressaltar que essa lista está aberta a acréscimos ou reduções em função de descobertas etnográficas acerca da semiologia descrita pel os informantes de cada pesquisa realizada. A lista originalmente concebida inclui os seguintes protótipos: depressão; violência contra si mesmo; violência contra os outros; comportamento bizarro; alucinação e delírio; convulsão; impulsividade; ansiedade; retraimento e iso- lamento; negligência; interação social inadequada; alteração da forma e do conteúdo do discurso; e retardo mental. Na pesquisa realizada em 1990, na Bahia, foi acrescentado o protótipo "alteração do olhar", fruto de achado etnográfico, e, na atual pesquisa, apareceu o protótipo comportamento sexual desviante como signo culturalmente rele vante. Esses achados associam-se a valores, significados e contextos culturais que fazem com que certos comportamentos indiquem, com maior ou menor expressividade, problemas no campo da saúde mental.

Seguindo a orientação do marco teórico acima assinal ado, foi realizada a pesquisa etnográfica em uma unidade de saúde da família e um centro de assistência psicossocial. A unidade de saúde da família estudada compunha-se de quatro equipes, situadas em um bairro do subúrbio ferroviário, em Salvador. Foi implantada em novembro de 2003, sendo que a última equipe começou a atuar nesta unidade em finais de 2004.

0 bairro em questão possui uma população de 73. 933 pessoas residentes, de acordo com o último censo do IBGE, realizado em 2000. Em relação à escolaridade, temos 55.435 pessoas alfabetizadas e 10.594 de pessoas não alfabetizadas. Tratase de uma área ocupada pela classe média baixa e baixa, com o predomínio dessaúltima. 0 índice de desemprego é significativo e problemas decorrentes do uso de álcool e outras drogas também se fazem presentes. Com relação a esse aspecto, vale destacar que a violência decorrente do tráfico vem aumentando nos últimos tempos, o que levou os profissionais do PSF a adotarem medidas de autoproteção; por exemplo, a equipe sempre conclui suas atividades até as 17:00h, pois, após esse horário, seria mais perigoso a circulação na área. Por esse motivo também, os agentes comunitários (muitos são da região) ocupam a importante tarefa de facilitar a penetração dos demais profissionais na comunidade.

Em termos de técnicas empregadas na produção de dados, foram realizadas entrevistas semi-estruturadas individuais com membros de cada cate goria profissional que compunha a equipe do PSF, além de grupos focais, nos quais os participantes foram agrupados de acordo com sua formação (agentes comunitários, nível técnico enível universitário). Na análise, cada entrevistado está identificado pelo código utilizado na pesquisa e pelo nível de formação. Assim, utilizaremos AC (para agentes comunitários); NT (para profissionais denível técnico) e NU (para profissionais de nível universitário).

Todo material produzido a partir dos instrumentos utilizados foi codificado com a ajuda do 
NUDIST (Non-numerical Unstructured Data Indexing Searching and Theorizing) e, posteriormente, analisado. A seguir, apresentamos os resultados principais sobre a dinâmica do cuidado em saúde mental na unidade do Programa de Saúde da Família investigada.

Resultados

\section{Signos do sofrimento mental}

Reconhecer os signos do sofrimento mental não parece uma tarefa difícil para os profissionais que atuam no PSF. Por outro lado, a partir desses signos, lançar hipóteses diagnósticas e, o mais importante, pensar em estratégias de ação são tarefas em que dificuldades, de ordem diversas, são evidenciadas.

A identificação do sofrimento, no entanto, é realizada a partir de alguns sinais que apareceram no discurso dos entrevistados e que relacionamos com os protótipos listados pelo marco teórico adotado. Em linhas gerais, os signos que tiveram maior destaque no discurso dos entrevistados diziam respeito à violência contra os outros; ao retraimento e isolamento; e a comportamentos bizarros- signos que retratam bem a diferença existente no modo pelo qual o sujeito que sofre estabelece seu laço social. É justamente essa diferença que, segundo Foucault ${ }^{7}$, ao ser capturada nas malhas de significação produzidas culturalmente, podevir a ser apreendida como doença mental ou não. A diferença produz um ruído de tal ordem no campo das interações sociais que acaba por "demandar" uma cobertura semântica, a qual si multaneamente nomeia o mal-estar e o circunscreve em um sentido específico.

Outro protótipo que se destacou foi o da depressão, havendo uma série de relatos sobre pessoas da comunidade que se encontram sofrendo em função da mesma. Parece que, nessa comunidade, encontra-se uma situação que reflete uma tendência contemporânea, na qual a depressão, ao lado da síndrome do pânico e do transtorno obsessivo compulsivo, tem aparecido com uma das formas de sofrimento mais comuns e ganho destaque na mídia. A intensa veiculação nos meios de comunicação de alguns transtornos aparece, vale ressaltar, concomitantemente, com o fortalecimento da psiquiatria biológica, a partir da década de 1980, como destaca H enning ${ }^{8}$. M ovimento queteve como uma de suas principais conseqüências a retirada de algumas categorias nosológicas do DSM (Diagnostic and Statistical Manual of M ental Disorders), publicação da Sociedade N orte-America- na de Psiquiatria. Dentre as mudanças operadas, uma das mais importantes foi certamente a substituição da neurose pelos transtornos de ansiedade, entre outros. 0 grande espaço que a depressão tem na mídia leva a uma proliferação de identificação de casos protagonizada tanto por profissionais de saúde mental como por aqueles que estariam na posição de "leigos". Chama a atenção, no entanto, que a depressão ganhe rel evância comparada a outros sofrimentos como o pânico e o TOC (transtorno obsessivo compulsivo) que, na realidade, não aparecem em nenhum relato.

Em relação ao protótipo da agressividade, surgiram relatos de situações nas quais um membro da comunidade se mostra agressivo na sede do PSF. Por vezes, tratava-se de sujeitos al coolistas que se encontravam sob efeito do álcool. Essas ocorrências costumam mobilizar muito a equipe, que recorre sempre à ajuda do agente de portaria ou mesmo da polícia: E também teve outro paciente que, além deleter problema mental, ele bebia muito, ele bebe muito; aí veio e agrediu o médico, queria bater no médico, e tudo. Suspendeu a mão para 0 médico, foi em cima mesmo, o médico segurou no braço dele eaí o segurança conseguiu conter ele, chamou o policial, o policial pegou etirou ele da unidade. (EIP02, NT)

0 relato acima destacado chama atenção por al guns motivos. Primeiro, fica visível o quão desconcertanteé, para a equipe, ter que gerenciar situações nas quais a agressividade se faz presente, sendo necessário recorrer àqueles que podem reprimir ou conter o sujeito de modo mais incisivo. Em segundo lugar, éinteressante observar que o al coolismo aparece como problema marginal no campo da saúde mental, escapando em al guns momentos ao seu domínio. Para entender o que se passa, podemos lançar a hipótese de que, se a doença mental como um todo nos coloca questões de ordem moral, parece que isso é acentuado em determinados tipos de sofrimento, como os de ordem compulsiva. O sujeito acometido pela compulsão (seja de beber, comer ou consumir) parece assim se portar devido a al gum tipo defraqueza da vontade, sendo, por conseqüência, portador de uma falha que parece essencialmente de ordem moral.

Retomando a discussão sobre os signos em seus aspectos mais gerais, é interessante observar ainda que, mesmo quando um possível signo do sofrimento psíquico aparece, podem surgir dúvidas se, na realidade, existeali um indício deum sofrimento que é mental, ou se tratar-se-ia de uma questão social: às vezes, édifícil para mim identificar se realmente é algum problema de saúde mental, ou se é confusão queeles vivem aqui, de pressão detráfico de 
drogas, devizinho quematou não sei quem. (GFP03, NU). U ma leitura que revela certo cuidado em não psicologizar qualquer indício de sofrimento. Nesse sentido, o profissional traz uma interpretação diferenciada em nossa época em que se percebe, claramente, a tendência a individualizar o sofrimento apresentado por um sujeito, através do recurso ao discurso "psi" que se encontra extremamente banalizado. Por outro lado, quando se coloca a questão se o sofrimento é de uma ordem ou de outra, perde-se um trânsito importante quenos permitiria pensar que o sofrimento social eo mental se apresentam freqüentemente relacionados de modo estreito. No campo da antropologia médica, por exemplo, Kleinman, Das e Lock ${ }^{9}$ propõem o rompimento dessa dicotomização que vem associada a uma série de outras polaridades: por exemplo, aquelas que separam os níveis individuais dos sociais deanálise, problemas sociais dos de saúde, representação de experiência, sofrimento de intervenção. [...] As dicotomias padrões são, na realidade, barreiras para compreender como as formas de sofrimento humano podem ser ao mesmo tempo coletivas e individuais, como os modos de experenciar a dor e o trauma podem ser simultaneamente locais e globais. [tradução nossa].

O caminho apontado pelos autores nos parece fértil, principalmente considerando a necessidade de formar profissionais que atuarão em contextos nos quais o sofrimento social adquire proporções significativas. Em tais situações, o sofrimento social possi velmente servirá como "matéria-prima" que, ao ser reeditado por cada sujeito, através de sua história e trajetória singular, alimenta o malestar que se manifesta no corpo e na psiquê.

\section{As formas de nomear: sofrimento,}

doença mental e outras categorias

Os signos acima apresentados foram relacionados com a doença mental, com o sofrimento mental, com o nervoso, com o problema de cabeça, entre outras categorias que surgiram no discurso dos entrevistados. Ao serem indagados sobre a diferença, mais específica, existente entre doença e sofrimento, as respostas, apesar de serem variadas, compartilhavam, em boa parte dos casos, da concepção de que a doença seria algo mais grave do que o sofrimento. Os seguintes extratos de narrativas nos parecem significativos nesse sentido:

Porque o doente é aquele que já tem, que já desenvolveu a doença e o sofrimento éalgo que se pode tratar maisfacilmentee que a pessoa pode se recuperar mais facilmente; ela ainda não está completamenteacometida, ela só está passando por um perío- do de sofrimento, mas eu acredito quea recuperação pode ser muito mais breve e rápida. (EIP05, AC)

Acho que doente mental é 0 que come cocô, que rasga dinheiro, que tem um comportamento agressi vo. E eu acho que sofrimento mental éde quem está momentaneamente passando por um problema que pode ser revertido. Eu acho. Eu acho que doente mental, na minha opinião de ignorante, que doente mental é uma coisa crônica. (EIP10, NU)

Duas outras concepções particulares também apareceram: (1) a doença se instala primeiro e 0 sofrimento vem como conseqüência e; (2) a doença está relacionada com uma questão social, enquanto o sofrimento seria uma patologia propriamente dita (exemplos de sofrimento seriam os quadros convulsivos e o retardo mental). A pesar dessas opiniões diferenciadas, prevalece uma cadeia associativa, na qual a doença mental aparece atrelada às noções de incurabilidade e cronicidade. No último relato acima destacado, encontramos ainda ressaltados os traços que identificam socialmente a figura do louco como sendo os mesmos que definem a doença mental.

A permanência maior da doença mental aparece, em certos momentos, relacionada com um suposto substrato orgânico que justificaria sua existência. A discussão da existência ou não deuma base orgânica para doença mental nos leva devolta para os primórdios da psiquiatria quando, de acordo com Becherie ${ }^{10}$, Pinel apostava na inexistência da organicidade, contrariando então a medicina anátomo-patológica que surgia então com os estudos de Bichat. Ter ou não fundamento orgânico é uma discussão que ganha velhos e novos ares com a psiquiatria biológica que aposta, hoje, em fal has nas sinapses, ou mesmo, em algum tipo de anomalia genética. Como destaca Conrad ${ }^{11}, 0$ projeto genoma, por exemplo, tem alimentado fortes esperanças, por parte de al guns, no sentido de descobertas etiológicas que levariam à potencialização das chances de cura.

As formas de fazer referência ao sofrimento mental, em linhas gerais, se mostraram extremamente variadas. Alguns recorreram a categorias da nosologia psiquiátrica, usando termos como depressão, psicose e pânico; enquanto outros fizeram um uso mais freqüente de categorias populares como "maluquinho", "problema mental", "Iou$\cos ^{\prime}$ e "nervoso". Uma diferenciação entre duas categorias nos chamou atenção: Elenão édoentemental, ele é nervoso, ele tem um problema de medo, precisa fazer alguma coisa para ocupar a mente! A pesar de não termos aprofundado a diferença proposta, o nervoso aparece como um sofrimento que, obedecendo à lógica anteriormente desta- 
cada, seria algo menos grave ou enraizado do que a doença mental.

\section{Causas do sofrimento mental}

Com relação às possíveis causas do sofrimento mental, vários fatores foram destacados, sendo que as questões sociais foram as mais evidenciadas. Se, em outro momento, apareceu a dissociação entre sofrimento mental e social, na discussão sobre a causalidade, os dois surgem em nova configuração, agora intimamente associados.

As condições socioeconômicas desfavoráveis apareceram como tendo um papel central no surgimento do sofrimento psíquico. Neste sentido, 0 desemprego e a fome tiveram um lugar de destaque: É a questão econômica queeu acho queéa base. $N$ ão adianta você ter uma família estruturada, com pai, mãe efilhos, todos vivendo na mesma casa, sendo o pai ea mãe desempregados, os meninos sem ter como ir para escola ou sem ter o que comer. Então, pra mim, assim, não tem outra coisa que venha interferir tanto na saúde mental das pessoas quanto 0 lado econômico. (EIP09, NT)

Além dos aspectos materiais relacionados à questão social, os vínculos familiares (sua fragilização ou mesmo dissolução) também apareceram como sendo elementos importantes. Um caso relatado nos parece emblemático nesse sentido: $\mathrm{Em}$ um caso que foi um acidente de um rapaz que tinha quarenta e cinco anos de idade, aí o filho usou drogas, a mulher foi embora e ele ficou com esse filho. Eletinha apenas um filho, ele ficou tão transtornado com a situação; a mulher, o filho, a vergonha, mas ele ficou para ele só. Então ele ficou quieto, então ele não saía mais, ele não trabalhava mais, não quis trabalhar, ficou assim, sabe? Abandonado. Tem pouco tempo, acho que oito dias que se jogou do ônibus e morreu. (GFP01, AC)

Ainda com relação à família, al guns entrevistados apontam sua importância na história do sujeito, sustentando, inclusive, a hipótese de que 0 sofrimento seja oriundo de um "trauma". Dentro do âmbito das situações traumáticas, alguns entrevistados apontaram o estupro como um importante causador do sofrimento mental. Parece nos interessante observar nos relatos sobre a hipótese traumática que os mesmos, ao sustentarem tal vertenteinterpretativa, apropriam-se, mesmo que sem saber, do discurso psicológico e, mais especificamente, do discurso psicanalítico. É fato conhecido que Freud, no início de suas investigações sobre a histeria, apostava na existência de uma experiência traumática, de cunho sexual, que re tornava, posteriormente, sob a forma dos sinto- mas neuróticos. N o entanto, segundo Quinet ${ }^{12}$, a teoria do trauma freudiana sofre uma reviravolta, quando Freud descobre o papel da fantasia na determinação do sofrimento neurótico.

Refletindo um pouco mais sobre essa apropriação de um discurso por outro, seria importante considerar como culturas diversas podem dialogar e realizar movimentos "antropofágicos", no qual sujeitos que pertencem e compartilham um mesmo sistema simbólico capturam el ementos presentes no campo semântico de outro grupo para ressignificá-lo a partir de suas próprias referências.

O sofrimento social, tomado como uma possível causa do sofrimento mental, mobiliza muito os profissionais. Como afirma, de modo emblemático, uma de nossas entrevistadas: Eu lido de uma maneira muito ruim, eu me sinto mal tendo que presenciar, tendo que conviver e na medida do possível, eu tento encontrar uma saída para amenizar a falta de dinheiro, a falta de condição, a falta de afeto. (EIP06, NU). Quando esse sofrimento diz respeito às condições materiais de existência, observamos que muitos tentam ajudar recorrendo, em al guns casos, a práticas assistenciais, como tentar viabilizar uma cesta básica ou mesmo doar roupas e outros bens.

Os valores da sociedade atual, especialmente os que dizem respeito ao consumo, foram apontados também como causadores de sofrimento. Isso porque a sociedade de consumo promoveria necessidades e ideais dificilmente alcançáveis, ainda mais na comunidade onde os profissionais atuam, em que as condições socioeconômicas são bastante desfavoráveis. Segundo um dos entrevistados, a sociedade assim configurada funcionaria como uma "cultura da doença", no sentido de que alimentaria o sentimento de frustração eimpotência dos sujeitos. As ressonâncias da sociedade contemporânea, fundada na lógica do consumo, teriam um impacto segundo al guns de nossos entrevistados no campo da ética, levando a uma fragilização das relações.

Dentre as várias possíveis causalidades para o sofrimento mental, as que apontavam para o campo social foram sensivelmente as mais ressaltadas. Outros elementos, como religião, surgiram de modo bastante secundário, quando, por exemplo, uma profissional se refere ao discurso de outra pessoa da comunidade que interpretou o sofrimento de uma pessoa próxima como decorrente de um trabalho feito no candomblé. Outros motivos, como hereditariedade, resguardo quebrado e pancada na cabeça, também fazem aparições pontuais. Em tempos nos quais as explicações biológicas adquirem uma força considerável, não deixa 
de ser instigante a preferência apresentada pelos nossos entrevistados que recorrem fundamentalmente a interpretações centradas nas questões sociais. Podemos hipotetizar que isso aconteça em decorrência de suas experiências profissionais e pessoais, bem como das características da comunidade onde atuam hoje, na qual tais questões se impõem com uma força significativa.

\section{A ocorrência do sofrimento -} os mais e os menos comuns

Como havíamos destacado anteriormente, a depressão foi a forma de sofrimento mais relatada e, segundo os profissionais, seria uma das patologias mais comuns, o que está de acordo com as tendências atuais. Outras situações destacadas foram ansiedade, epilepsia e deficiência mental. Alguns termos não classificados comumente como sofrimento ou doença mental, como negligência e "desorientado", também apareceram. Autismo e esquizofrenia foram apontados por um entrevistado apenas e, nesse caso em particular, a resposta surpreende, por um lado, pela baixa incidência desses "transtornos mentais" entre a população de um modo geral e, por outro, pelos signos mais destacados pelos próprios entrevistados que, em sua maioria, não remetiam a quadros psicóticos. No entanto, observamos a existência de opiniões bem divergentes. Se um sujeito apontou o autismo e a psicose como recorrentes, alguns outros, diretamente ou indiretamente, afirmaram que tais situações não são assim tão freqüentes. Do mesmo modo, encontramos os que disseram que retardo e quadros convulsivos são incomuns, contrapondo-se, desse modo, aos que consideravam tais quadros com significativa incidência na comunidade. Esse aparente "desencontro" pode ser tomado como mais um sinal de que, para a equipe do PSF envolvida na pesquisa, identificar o sofrimento mental, bem como construir um discurso compartilhado sobre o mesmo, tem sido um desafio não realizado.

O utra consideração importante é que, ao indagarmos diretamente sobre as formas de sofrimento mais e menos comuns, não foi dado nenhum destaque aos casos de alcoolismo e uso de outras drogas. Contudo, uma série de relatos aparecem no decorrer das entrevistas que nos fazem pensar que tais situações têm uma ocorrência significativa. A exclusão dos usuários de drogas das respostas sobre ocorrência do sofrimento reforça uma hipótese anteriormente lançada, segundo a qual encontramos, nesses casos, uma tendência a perceber o comportamento do sujeito que faz uso dessas substâncias como decorrente de um tipo de fraqueza moral, o que o coloca à margem dos que padecem de outras formas de sofrimento.

\section{0 registro do sofrimento mental}

Durante a realização da pesquisa, um dos fatos que mais chamou atenção foi justamente a ausência de registros, nos prontuários, dos casos de sofrimento mental. M esmo quando famílias atendidas pelo PSF têm um de seus membros internado em um hospital psiquiátrico, não existe a prática de documentar tais acontecimentos. Uma entrevistada explica a ausência de anotações dizendo que: 0 s pacientes mentais só entram mesmo na ficha de cadastro que a gente coloca como doença referida (EIP08, AC). O u seja, para que o registro seja realizado, seria preciso que o próprio sujeito se declarasse portador de uma doença mental ou, mesmo, que sua família o fizesse. Apesar de não desconsiderar a importância e pertinência dessa explicação, outros relatos nos fizeram compreender melhor a dificuldade detectada: Cheguei com medo efalei pra minha enfermeira. Então ela disse que não tinha, não tem como dar assistência a um paciente psiquiátrico, então a gente deixou ela como se não tivesse cadastrado. (EIP10, NU). Outra entrevistada narrou o caso de uma senhora que, por apresentar uma situação de sofrimento intenso, seria incapaz de relatar o que se passa com ela: Ela sozinha, não dá para fazer isso, porqueela teria queter um esposo, um filho, alguém quefosse, quepassasse as situações, se ela tá melhorando, se não tá. É como quando tá criança em casa; se só tiver adolescente, a gente não pode cadastrar (GFP01, AC). Encontramos, nesse último relato, uma associação entre doença mental - infantilidade - incapacidade de responder por si. Tal associação foi destacada e discutida por Foucault ${ }^{7}$, que encontra, nessa aglutinação, uma forte justificativa social para a destituição do dito "louco" de sua cidadania e, em decorrência, para a afirmação esolidificação das práticas detutelagem.

A questão do cadastrar ou não o portador de sofrimento mental é um importante sintoma do desconcerto vivenciado por alguns profissionais ao se depararem com esse sujeito; fato que não se restringe ao PSF que investigamos. Encontramos, na bibliografia pesquisada, o relato de uma agente comunitária ${ }^{13}$ que retrata justamente a mesma angústia sobre o cadastramento:

No princípio, relutei em fazer o cadastro dele por medo e por achar que não teria nada que fazer por ele aqui no Posto de Saúde. M esmo assim, no dia 20 de março de 1998, eu fiz o cadastro com informações dadas pelo pai de Leão. Ele explicou os problemas do 
filho, os remédios que tomava e, cada vez mais, eu me convencia de que a Equipe não podia fazer nada por ele.

Outro elemento que aparece, de modo visível, no primeiro discurso destacado, é o medo, sentimento presente e relatado por muitos profissionais. 0 medo, agregado ao sentimento de impotência, por não saber lidar com os casos de sofrimento mais intenso, faz com que os portadores de transtorno mental recebam um tratamento diferenciado. Por exemplo, quando os mesmo vão até o posto para fazer um curativo, os técnicos evitam fechar a porta do consultório, ou mesmo, em alguns casos (como o de alcoólatras) solicitam a presença do agente de portaria para se sentirem mais seguros. Eis um exemplo no qual o agente de portaria é solicitado: [uma profissional, relatando o caso de um paciente se mostra mais agressivo, descreve sua atitude:] M ostro a ele que eu não tô com medo dele, não tô sentindo nenhuma ameaça por ele. Faço o que ele quer e mando ele ir embora. A gora, quando ele realmentequer partir pra agressividade e a gente tá percebendo que ele vai agredir, a gente pede já pro agente de portaria tomar a frente. Aí eu caio fora [risos], pra não tomar a galinha pulando (EIP02, NT).

A sensação demedo vivenciada por alguns profissionais nos remete a um modo de perceber que associa a figura do "Iouco" à imagem de um sujeito "perigoso". Nesse sentido, uma entrevistada usa o termo "traiçoeiros" para fazer referência aos pacientes psiquiátricos que seriam "bonzinhos" em um dado momento para, logo em seguida, apresentarem um comportamento agressivo.

\section{A relação dos profissionais com a comunidade}

A relação entre profissionais e comunidade é marcada pela ambigüidade e sofre variações consideráveis de acordo com o profissional em questão. D entre os entrevistados, os agentes comunitários, por pertencerem originalmente ao bairro, e pela natureza da atividade que realizam, são os profissionais que estão mais próximos da população de um modo geral. De qualquer modo, essa proximidade não os exime também de estabelecer uma relação ambígua - ora se sentem valorizados por estarem zelando pela saúde da comunidade e por servirem como referência para os habitantes do bairro, ora reclamam por não serem escutados eacolhidos por parte de alguns como gostariam. Cabe aos agentes comunitários, no entanto, a maior parte da tarefa de criar o vínculo entre PSF ea comunidade, preparando-a, inclusive, para as possíveis idas ao posto. Por exemplo, em um diário de campo, registrou-se a seguinte orientação fornecida por uma enfermeira para os agentes comunitários: Diz que é preciso educar, explicando que os ACS devem passar a dizer às pessoas de sua área, caso eles cheguem nervosos ebrigando, el es não serão atendidos, devendo primeiro ficar calmos. A função apaziguadora atribuída aos agentes parece ocorrer devido ao incômodo, bastante presente entre os técnicos e os profissionais de nível superior, que se queixam dos pacientes que chegam mais agressivos ou querendo atendimento imediato. A mudança do regime de funcionamento do que outrora fora um posto de saúde e, hoje, funciona como sede do PSF parece não ter sido acompanhada por uma mudança cultural na comunidade, o que dificulta de modo significativo à relação que essa estabelece com a unidade. Trata-se de expectativas que nem sempre são satisfeitas. Um desencontro entre oferta edemanda, poder-se-ia afirmar. Nesse sentido, o contato com as lideranças comunitárias foi apontado por um profissional como uma estratégia que tem rendido frutos: Eu lembro de uma líder comunitária, no início, quando a gente começou pra agora, o discurso dela mudou totalmente. Ela agora compreende o PSF, compreende tudo e sabe que a instalação do PSF aqui não foi uma das melhores, estrategicamente não foi, mas antes eu achava que ela tinha um discurso muito duro, eagora não. A última reunião que eu participei, ela muito tranqüila, calma, serena, falando que existe dificuldade, mas que a comunidade tinha que passar a entender o que era o programa, que o programa éisso, isso eisso. Pode ter demorado um ano, mas alguma coisa se conseguiu. (EI P06, NU)

Para al guns profissionais, é preciso ainda muito trabalho no sentido de "criar o vínculo" da comunidade com a unidade de saúde, ou ainda, incrementar a participação da mesma na resolução dos problemas no nível de saúde da família. A percepção de que é preciso avançar nesse sentido não parece ter sido acompanhada de estratégias mais sistemáticas para fortalecer o laço. Os profissionais ressaltam ainda que, para convocar a comunidade e realizar qual quer atividade extra, énecessário dar algo em troca, que não seja apenas a prestação de serviço em prol da promoção da saúde. Lanches, por exemplo, é um dos recursos utilizados para garantir a presença das pessoas. A postura de quem espera um benefício imediato éalgo que causa incômodo, mas que, ao mesmo tempo, os profissionais parecem não conseguir manejar de modo adequado. É preciso considerar que se trata de uma postura incorporada cultural mente e que demandará tempo e esforços de ambas as par- 
tes para ser desconstruída. Para iniciar esse processo, os profissionais precisam negociar com a comunidade, o que de certo modo tentam fazer, mas seria de grande utilidade se conseguissem ter um direcionamento compartilhado em termos de condutas adotadas.

Em alguns momentos, as queixas da comunidade chegam até o distrito, que cobra da equipe posicionamentos sobre os fatos relatados. Por exemplo, a equipejá parou 0 atendimento externo às quinze horas para realizar uma reunião. Um membro da comunidade ligou para o distrito denunciando que "a vacina fechou às três horas". Em seguida, o coordenador do posto foi indagado sobre o ocorrido e teve que prestar os esclarecimentos solicitados. Esseacontecimento gerou malestar, pois al guns se sentem excessivamente vigiados e aprisionados num regime de trabalho no qual pausas não são permitidas. Mais uma vez, mostra-se necessário um estreitamento dos laços entre comunidade e PSF, para que uma relação de confiança possa real menteser estabelecida, suplantando os sentimentos de perseguição e insatiffação tanto de um lado quanto de outro.

O utro elemento que se destaca na relação entre equi pee comunidade diz respeito ao temor da violência no bairro. A sensação de medo vivenciada pelos profissionais de saúdenessa comunidadenão é, atualmente, uma exceção. Infelizmente, tem sido a regra para muitos que desenvolvem suas atividades entreas camadas mais desfavorecidas da população, nas quais a violência adquire, por vezes, uma maior visibilidade. Seria, talvez, interessante, começar a pensar com essa equipe que a violência também éuma questão de saúde pública e que, apesar do medo experenciado, algo pode ser pensado e feito nesse sentido pelos profissionais do PSF.

\section{Considerações finais}

A presentamos, em linhas gerais, os signos, os significados eas práticas de quatro equipes do PSF atuantes na periferia de Salvador. Observamos que os integrantes das equipes tentam, a partir dos recursos de que dispõem, lidar com situações nas quais o sofrimento mental se faz presente; entretanto, vivenciam, nesse sentido, uma série de dificuldades.
Um aspecto que se destaca é a pluralidade pre sente nas formas de identificar e nomear o sofrimento. A pesar de sabermos que a diversidade interpretativa faz parte de toda equipe multidisciplinar de saúde, o grau de polissemia encontrado nos faz pensar que, no tocanteà saúdemental, os profissionais não compartilham uma linguagem comum. I sso dificulta, certamente, o trabalho da equipe.

Dentre esses impasses, sentimos que os profissionais se sentem despreparados para manejar as situações em que o sofrimento mental aparece, sendo inclusive detectada uma situação na qual não se registrou um caso identificado na comunidade. A ausência de registro, no contexto que nos foi relatada, revela um desconcerto do profissional ao se deparar com situações perante as quais ele não se sente suficientemente capacitado para atuar. Foi possível verificar também que, em alguns momentos, os profissionais se incomodavam particularmente com os sujeitos dependentes do álcool e com os que se mostravam violentos.

Por outro lado, é de fundamental importância ressaltar que os profissionais se mobilizam com tais situações; em hipótese alguma podemos confundir suas angústias com uma apatia frente ao sofrimento mental de membros da comunidade. 0 que percebemosfoi uma visível sensibilidade, desenvolvida em maior grau por alguns profissionais, com relação não apenas ao sofrimento psíquico, mas sobretudo com relação ao sofrimento social. No entanto, as ações para efetivar o cuidado em saúde mental ainda acontecem de modo isolado.

É urgente que desenvolvamos al gumas estratégias que possam auxiliar as equipes de PSF a entrarem na rede de cuidados, inclusive, em saúde mental. Cursos de capacitação seriam úteis no sentido defacilitar a transmissão de conhecimentos importantes acerca da reforma psiquiátrica e do próprio sofrimento mental, o que auxiliaria esses profissionais a desenvolverem um idioma comum que lhes possibilitasse compartilhar al gumas percepções. No entanto, formas de ajuda mais permanentes como um supervisor ou uma equipe de profissionais a quem o PSF pudesse recorrer para melhor pensar como trabalhar as situações referentes ao sofrimento mental (que poderia ser a de um CAPS), identificando inclusivequal o momento em que o encaminhamento para um serviço especializado se faria necessário, fariam uma grande diferença. 


\section{Colaboradores}

VJ Jucá participou da concepção do artigo. MO N unes e SG Barreto foram responsáveis pela revisão final do texto e por um detalhamento maior dos aspectos metodológicos. Todas as autoras participaram das diversas fases da pesquisa em questão, coordenada por MO Nunes.

\section{Referências}

1. Vasconcelos EM. Desinstitucionalização e interdisciplinaridade em Saúde M ental. Cadernos do IPU B 1997; 7:17-39.

2. Cordeiro H. O PSF como estratégia de mudança no modelo assistencial do SUS. Cad Saúde Pública 1996; 1:10-15.

3. Lancetti A, organizador. Saúde Loucura 7: Saúde Mental e Saúde da Família. 2ª ed. São Paulo: Hucitec; 2001.

4. Oliveira M, Colvero L. A Saúde M ental no Programa de Saúde da Família. [acessado 2006 mar 17]. Disponível em: http://www.ids-saude.uol.com.br

5. Almeida-Filho N, Corin E, Bibeau G. Signs, meanings and practices in mental health: methological application. The Bahia Study. Texto inédito 1998.

6. Almeida-Filho N, Corin E, Bibeau G. Rethinking transcultural approaches to mental health research: from epistemology to methodology. Texto inédito 1999

7. Foucault M. Doença mental e psicologia. Rio de Janeiro: Tempo Brasileiro; 1994.

8. Henning M F. Neuroquímica da Vida Cotidiana. Cadernos IPU B 2000; 18(4):123-132.

9. Kleinman A, Das V, Lock M. Social suffering. Berkeley: University of California Press; 1997.

10. Bercherie P. Os fundamentos da clínica: história e estrutura do saber psiquiátrico. Rio de Janeiro: Zahar; 1989.

11. Conrad P. Genetic Optimism: Framing Genes and $M$ ental IIIness in the News. Culture, Medicine and Psychiatry 2001; 2(25):225-247.

12. Quinet A. A lição de Charcot. Rio de Janeiro: Zahar; 2005.

13. Mattos AF. Entre a loucura e a liberdade: a experiência de uma agente comunitária de saúde. In: Lancetti $A$, organizador. Saúde Loucura 7: Saúde M ental e Saúde da Família. 2aed. São Paulo: Hucitec; 2001. p. 53-58.

Artigo apresentado em 26/04/2006

Aprovado em 03/02/2007

Versão final apresentada em 08/05/2007 